\title{
Proof-of-concept trial of the portable electronic nose PEN3 for detection of formic acid concentration in the beehive
}

\author{
Antonia Genath ${ }^{1)}$, Michael Hofmann ${ }^{2)}$, Carlo Tiebe ${ }^{2)}$, Ralf Einspanier ${ }^{1)}$ \\ 1) Institut für Veterinär-Biochemie, Freie Universität Berlin, Oertzenweg 19 b, 14163 Berlin \\ T: +49 30 838-62575, E: antonia.genath@fu-berlin.de, ralf.einspanier@fu-berlin.de \\ ${ }^{2)}$ Bundesanstalt für Materialforschung und -prüfung (BAM), Unter den Eichen 44-46, 12203 Berlin \\ T: +49 30 8104-4518, E: michael.hofmann@bam.de, carlo.tiebe@bam.de
}

\begin{abstract}
Formic acid (FA) treatment as measure against the ectoparasitic mite, Varroa destructor, which infests the western honey bee, Apis mellifera, is usually performed twice a year. Although the therapeutic index is very narrow and the success of FA-treatment is highly dependent on various external factors, little is known about the local FA concentrations occuring in the hive. In this study we examined whether a commercially available odour measuring device ("electronic nose") is suitable for measurements of high FA concentrations, as present during treatment. As measuring systems, two different setups were prepared for detection of FA concentrations in gas mixtures: A polymethyl methacrylate (PMMA) box was used to investigate whether the electronic nose is able to distinguish between different FA concentrations and a two-storied Segeberger hive to test under realistic conditions during bee-keeping. In both experimental systems, the signals from the same sensor components (sensor type no. 1, 6, 7, 8 and 9) showed an increased sensitivity towards the presence of FA in the gas mixture. Principle component analysis (PCA) and linear discriminant analysis (LDA) allowed for identification of specific patterns in the measurement signals and showed clear correlations between the signals and the present FA concentration. These results indicate that the introduced commercial multi gas sensor system is suitable for detection of high FA concentrations, and therefore could be a starting point developing a detection method of FA. The future aim is to successfully monitor the efficiency and effectiveness of this anti-varroa-treatment.
\end{abstract}

Keywords: Apis mellifera, Varroa destructor, Formic Acid, Metal-Oxide Gas Sensor Array

\section{Introduction}

Varroosis, caused by the ectoparasite Varroa destructor, is considered as one of the most important pests of the western honey bee, Apis mellifera. The mite causes considerable damage to its host, directly imparing the fat body tissue and indirectly by transmitting several harmful viruses and bacteria [1, 2, 3]. A colony infested with $V$. destructor will die within 2 to 3 years of the initial infestation if left without treatment [4].

Formic acid (FA) has been used mainly by beekeepers for decades as a treatment against V. destructor [5]. $60 \%$ concentrated FA in water is applied in the beehive using different types of evaporators and acts in the gas phase. As FA is capable of penetrating the wax into the capped brood, it is the only miticide effective not only against the adult mites (on adult bees) but also the reproductive stages of the mite (in the sealed brood) [6]. Other advantages include that the mites are unlikely to develop resistance as well as the low risk of residue problems in bee products $[1,6,7]$.

However, the therapeutic index - the range between efficiency against the mites and damage of the bees - is very narrow [8] and the therapy success is highly dependent on environmental factors, such as temperature and humidity as well as other influencing factors (e.g. bee colony size, type of application, concentration of FA and hive shape) [1].

Therefore, an accurate evaluation of the local FA concentration during treatment is necessary to either determinate the optimum efficiency of FA and/or to allow for immediate beekeeping intervention if the maximum concentration is exceeded.

The development of a screening method for estimation of actual FA concentrations in the 
beehive would provide a major advance not only in honey bee health related research, where an exact determination of the FA concentration is necessary for generation of precise research results. Furthermore, professional beekeepers get the oppurtunity to monitor the therapy success during varroa control without beeing exposed to potentially harmful FA concentrations.

The long-term objective of this study is to develop a suitable and affordable device, which can be used particularly for beekeeping practices but also for scientific purposes. The commercially available electronic nose PEN3 (PEN3, AIRSENSE Analytics GmbH, Schwerin) provides the basis for further development.

The aim of the preliminary tests was to check whether PEN3 is suited to detect such high FA concentration in a gas mixture under similar conditions present in the beehive during FA treatment.

\section{Material and Methods}

Two different systems were prepared as measuring stations for detection of FA concentration in gas mixtures:

A) A PMMA box with a volume of $1.9 \mathrm{~L}$, which was supplied with a gas flow of humidified synthetic air $\left(50 \mathrm{~mL} \mathrm{~min}^{-1}\right.$, $100 \mathrm{~mL} \mathrm{~min}{ }^{-1}, 300 \mathrm{~mL} \mathrm{~min}{ }^{-1}$ ), operated as a test chamber (Fig. 1). The humidity is generated by flushing synthetic air through a humidifier at $210 \mathrm{kPa}$. The humidified synthetic air is decompressed to ambient pressure. The dew point temperature of this humidified gas is $13.3{ }^{\circ} \mathrm{C}$ at ambient pressure (1013 hPa). To generate a temperature of $25^{\circ} \mathrm{C}$ the box was placed on a temperature-controlled heating mat or in an oven to generate a temperature of $35{ }^{\circ} \mathrm{C}$, respectively. A glass dish (surface of liquid phase: $9.6 \mathrm{~cm}^{2}$ ) containing different concentrations of FA in deionised water (0\% to100 \%) was placed within the system.

Each measurement was conducted after ten air exchanges and repeated three times, starting with blank value determination and subsequently increasing concentrations of $\mathrm{FA}$ in water $(0 \%, 20 \%, 40 \%, 60 \%, 80 \%$, $100 \%)$.

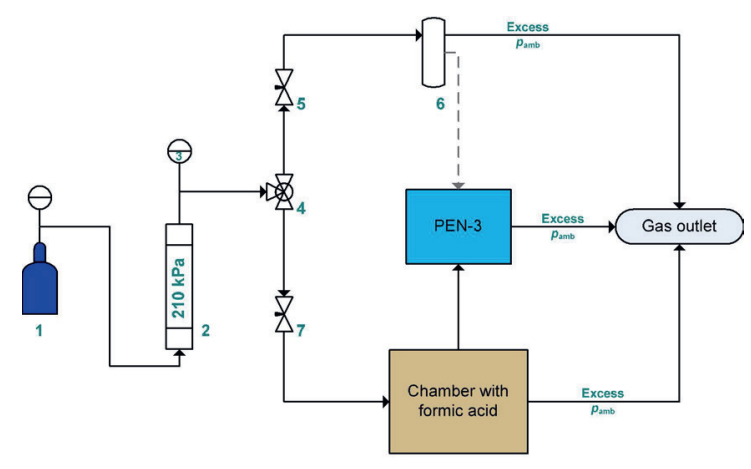

Fig. 1: Flowchart of FA detection in a measuring chamber (PMMA box). 1 - synthetic air, 2 - humidifier (water reservoir at $\left.p=210 \mathrm{kPa}, t=23^{\circ} \mathrm{C}\right), 3$ - manometer, 4 - union tee, 5 control valve, 6 - gas cylinder and tube to zero-air measurement, 7 control valve.

B) A two-story polystyrene Segeberger hive compromising two boxes, a lid and a walking floor with floor grid (Fig. 2), containing eight filled honey frames per level was placed on a heat mat to generate a temperature of $25^{\circ} \mathrm{C}$. $60 \%$ FA was applied by means of a specially designed evaporator (Nassenheider Evaporator Universal R). To avoid pollution in the surrounding area, the system was placed under a fume hood. Measuring points were drilled into the chest (three in the upper story, one in die lower story) in order to determine the FA concentration at distinct locations inside. The measuring points were connected with the analyser via PTFE (Polytetrafluoroethylene) hoses with a length of $30 \mathrm{~cm}$, an outer diameter of $4 \mathrm{~mm}$ and a wall thickness of $0.5 \mathrm{~mm}$. The gas phase in the hive was tested by PEN3 at distinct sampling times ( $1 \mathrm{~h}, 2 \mathrm{~h}, 3 \mathrm{~h}, 4 \mathrm{~h}, 24 \mathrm{~h}$ ) at four sampling points until an equilibrium concentration of FA was established. 


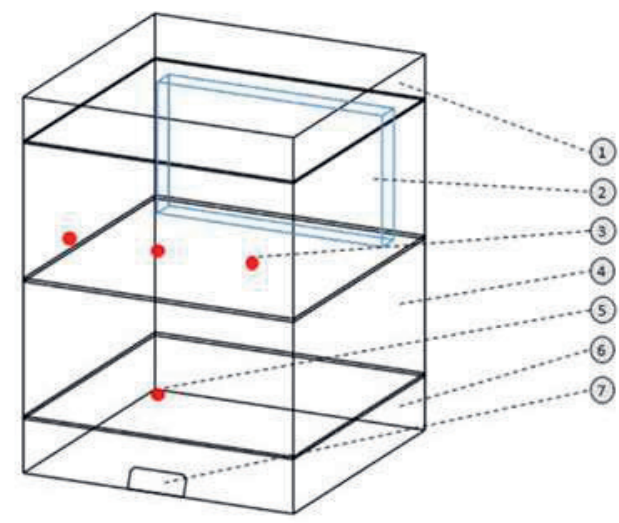

Fig. 2: $\quad$ Sketch showing Type B) measuring station for detection of FA concentration in gas mixtures. 1 - lid $(50 \mathrm{~cm} \times 50 \mathrm{~cm} \times 10 \mathrm{~cm})$, 2 - Nassenheider ${ }^{\circledR}$ Evaporator Universal R), 3 - measuring points upper story $(1-3), 4-$ body $(50 \mathrm{~cm} \times$ $50 \mathrm{~cm} \times 22.3 \mathrm{~cm}), 5$ - measuring point lower story (4), 6 - floor (50 × $50 \times 10$ $\mathrm{cm}), 7$ - flight hole.

Tab. 1: Sensor types and detectable substance groups of the metal-oxide gas sensor array.

\begin{tabular}{|c|c|c|}
\hline No. & $\begin{array}{l}\text { Sensor } \\
\text { type }\end{array}$ & $\begin{array}{l}\text { Substance } \\
\text { group }\end{array}$ \\
\hline 1 & W1C & Aromatic compounds \\
\hline 2 & W5S & Broadband \\
\hline 3 & W3C & Aromatic compounds \\
\hline 4 & W6S & Hydrogen \\
\hline 5 & W5C & $\begin{array}{l}\text { Aromatic and aliphatic } \\
\text { compounds }\end{array}$ \\
\hline 6 & W1S & Broadband, methane \\
\hline 7 & W1W & $\begin{array}{l}\text { Organo-sulfur } \\
\text { compounds }\end{array}$ \\
\hline 8 & W2S & Broadband, alcohols \\
\hline 9 & W2W & Sulfur chlorides \\
\hline 10 & W3S & $\begin{array}{l}\text { Methane, aliphatic } \\
\text { compounds }\end{array}$ \\
\hline
\end{tabular}

PEN3, an instrumented odour measuring device containing an array of chemical sensors and a pattern recognition software, was used for detection of the FA-gas-mixture. An internal pump was transferring the measuring gas mixture to the internal 10 -fold metal-oxide gas sensor array (Tab. 1). For dilution purified synthetic air (system A) and ambient air (system B) were utilized as zero-gas and swept over the sensor array. The generated sensor signals describe a resistance ratio between the resistance value for each sample-gas $(R)$ and zero-gas $\left(R_{0}\right)$ measurement. Gases in varying concentrations and compositions can be recognized by their signal pattern and distinguished from another.

\section{Results}

In order to estimate the order of magnitude of the FA mass concentration in a Segeberger hive, generated by the Nassenheider Evapaporator Universal R, a theoretical consideration based on the balance equation of an ideal continuous batch reactor with constant emission source $[9,10]$ the following equation was used:

$$
\frac{d \beta(t)}{d t}=\frac{E}{V}-n \cdot \beta(t),
$$

where $\beta$ is the mass concentration of FA in air in $\mathrm{mg} / \mathrm{m}^{3}, E$ is the evaporation rate of $F A$ in $\mathrm{mg} / \mathrm{d}, n$ is the air change rate in $1 / \mathrm{d}, V$ is the free volume in $\mathrm{m}^{3}$ and $t$ is the time in $\mathrm{d}$. The solution of the differential equation under the boundary condition $\beta(0)=0$ results as follows:

$$
\beta(t)=\frac{E}{n \cdot V} \cdot\left(1-e^{-n \cdot t}\right) .
$$

The volume of the hive according to the internal dimensions (Fig. 2) without honey comb frames is $35.2 \mathrm{~L}$. According to the data sheet of Nassenheider Evaporator Universal R [9], a $60 \%$ FA volume of $180 \mathrm{~mL}$ is sufficient for an application period of $12 \mathrm{~d}$. Hence, the daily consumption of $60 \% \mathrm{FA}$ in water solution is $15 \mathrm{~mL} / \mathrm{d} \pm 3 \mathrm{~mL} / \mathrm{d}$, which - with a FA density of $1.2273 \mathrm{~g} / \mathrm{cm}^{3}$ - results in an evaporation rate of $11.1 \mathrm{~g} / \mathrm{d} \pm 2.2 \mathrm{~g} / \mathrm{d}$ of FA.

The bees inside the hive generate a homogeneous distribution of $\mathrm{FA} /$ water vapour as well as an air exchange by the bee fanning. As a result, FA will reach even the brood in covered cells and an equilibrium concentration of FA in air is established in dependence on the air change rate.

Based on equation 2 and the assumptions made, FA mass concentrations in air of $2620 \mathrm{mg} / \mathrm{m}^{3}$ to $26200 \mathrm{mg} / \mathrm{m}^{3}$ in the hive are established at air change rates of $0.5 \mathrm{~h}^{-1}$ to $5 \mathrm{~h}^{-1}$ (Fig. 3).

The estimated mass concentrations of FA in the air of a hive are very high and above the range of the routine measurement range of available gas sensor elements or absorption test tube methods, e.g., for monitoring of maximum workplace concentrations - MAK value, which is 
$9.5 \mathrm{mg} / \mathrm{m}^{3}$ [11]. The direct sensor-supported measurement requires a problem-solving sampling strategy for the detection of FA in air.

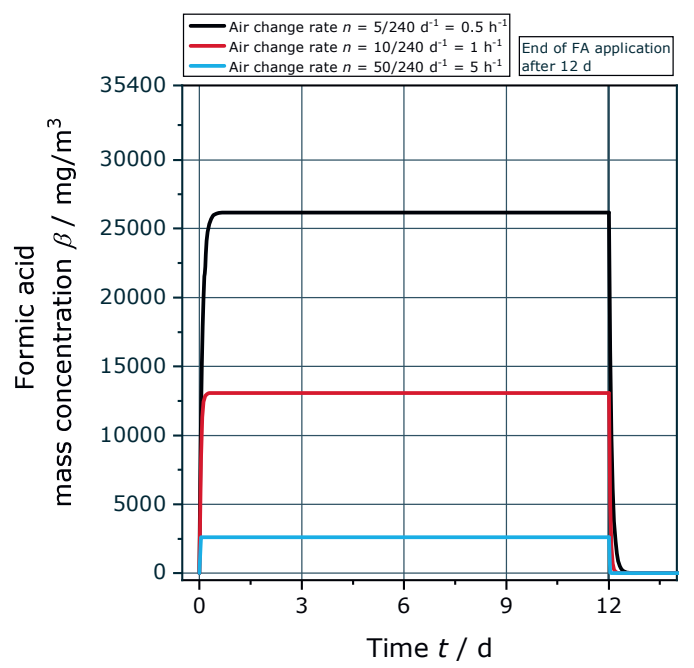

Fig. 3: Theoretical mass concentration course of formic acid over time during the FA-application.

In both experimental setups the signals from sensor components 1 (aromatic compounds), 6 (broadband, methane), 7 (organosulfur compounds), 8 (broadband, alcohol) and 9 (sulphur chlorides) showed an increased sensitivity towards the presence of FA in the gas mixture. The sensor elements 6,8 and 9 generated the greatest resistance ratios and could therefore be assumed the most sensitive components.

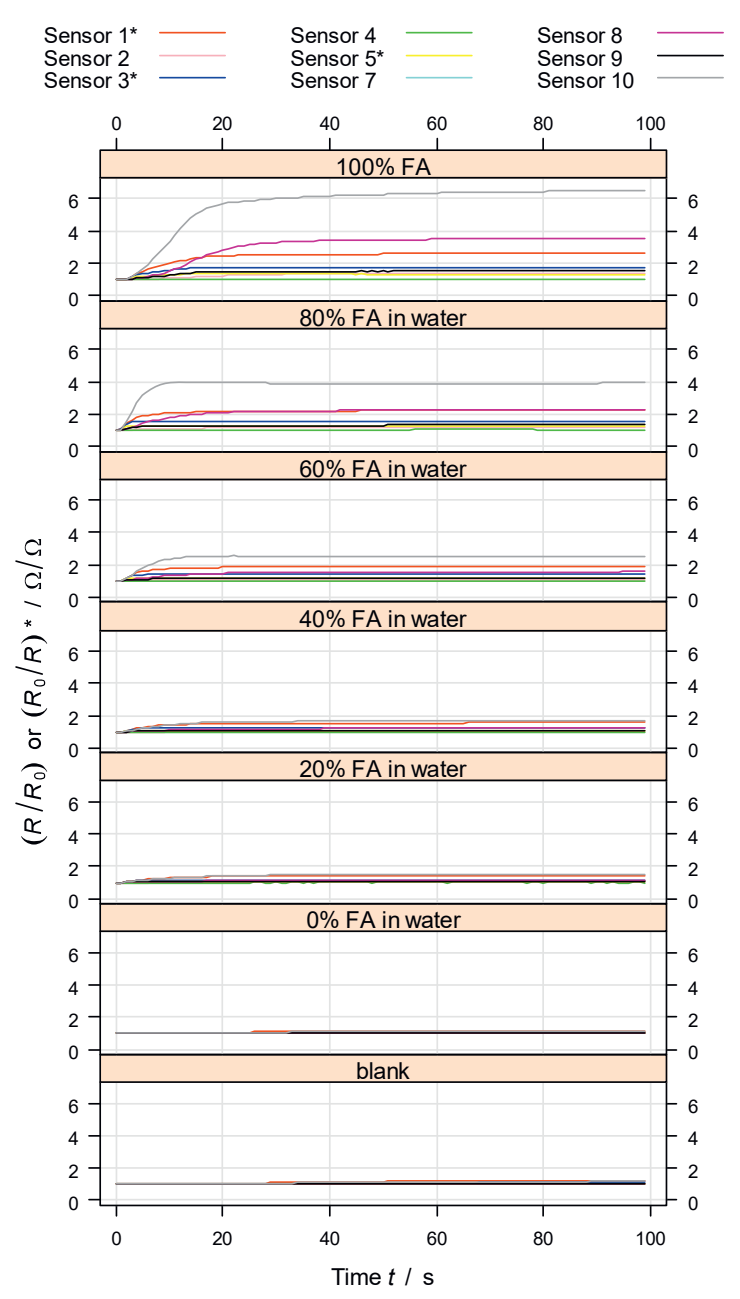

Fig. 4: Sensor sensitivities towards the presence of $F A$ in the experimental setup type $A$ at $35^{\circ} \mathrm{C}$.

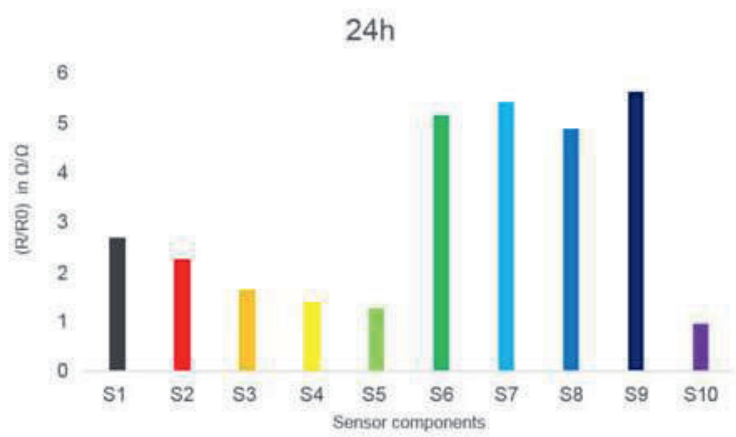

Fig. 5: FA-measurement implemented after $24 \mathrm{~h}$ in experimental system type $B$ at $25{ }^{\circ} \mathrm{C}$. In both systems signals from sensor components 1, 6, 7, 8 and 9 display clear dependence on FA concentration. 
In order to identify specific patterns in the measurement signals, statistical methods like principle component analysis (PCA) and linear discriminant analysis (LDA) were conducted subsequently based on the generated data.

Figure 6 shows PCA- and LDA-plots of the most important components PC1/ PC2 and LD1/ LD2, respectively, performed on the measurement data generated during a test run in test system $A$ with a temperature of $35^{\circ} \mathrm{C}$, a gas flow rate of $300 \mathrm{~mL} \mathrm{~min} \mathrm{~m}^{-1}$ and different concentrations of FA in water (0 - 100\%).

Clearly recognizable are the dependencies of PC1 and LD1 (abscissa) on the presented FA concentration.

A

- DI water $\bullet 0 \% \cdot 20 \% \quad 40 \% \quad 60 \% \quad \bullet \quad 80 \% \quad \bullet 100 \%$

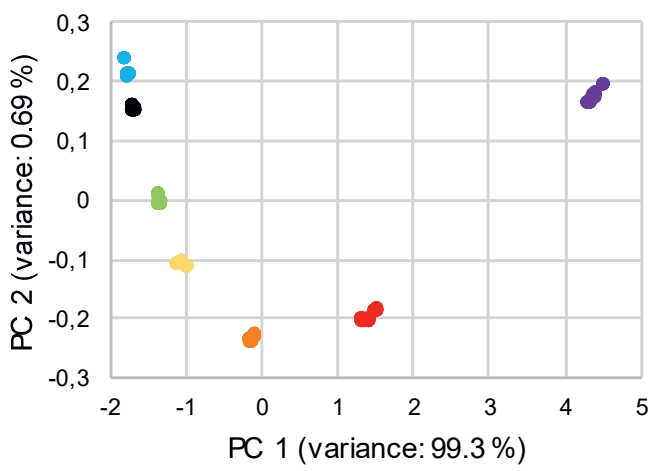

B
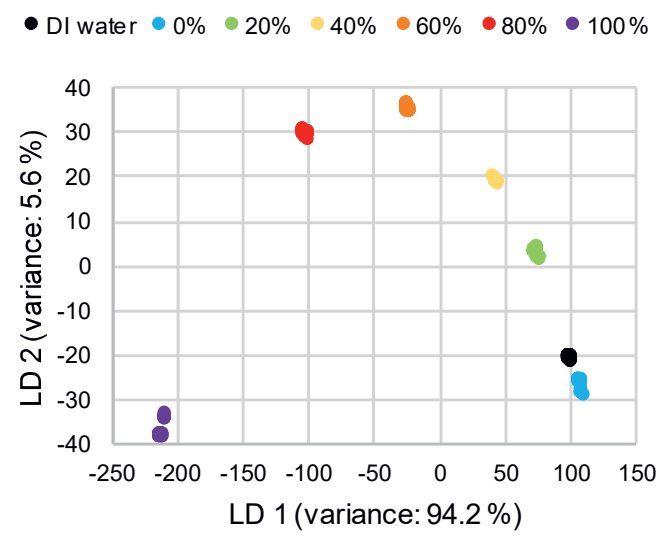

Fig. 6: $\quad P C A(A)$ and $L D A(B)$ results of setup type $A$ at $35{ }^{\circ} \mathrm{C}$, a gas flow rate of $300 \mathrm{~mL} / \mathrm{min}$ and different $F A$ concentrations in water. Basis of this calculations are the steady state resistance values in the measurement time range $85 \mathrm{~s}$ to $95 \mathrm{~s}$ (Fig. 4).

These preliminary results demonstrate that the multi gas sensor system PEN3 is suitable for detection of high FA concentration in gas mixtures under similar conditions to those applicable in a honey bee hive during FA treatment.

\section{Discussion/Vision}

Our initial results show that metal-oxide gas sensor arrays, like those used in PEN3, are suitable for detection of FA in gas mixtures even in high concentrations, which exceed MAK value $\left(5 \mu \mathrm{mol} / \mathrm{mol}\right.$ equal to $\left.9.5 \mathrm{mg} / \mathrm{m}^{3}\right)$. This feature allows an application in hives during $F A$ treatment, where it cannot be excluded that exceptionally high concentrations of FA could potentially corrode or in some way harm the sensor systems.

Additionally, this type of test system is remarkable for their practical relevance due to the possibility of real-time data generation. A low cost alternative of this high-sophisticated commercially available sensor components may be of interest increasing its portability and miniaturisation.

Further investigation are required concerning the cross-sensitivities towards testparameters like temperature, humidity, air exchange rate and other chemical compounds, which frequently occur in hives.

Moreover, this system still needs to be validated, calibrated and tested for its reliability in subsequent field trials and laboratory tests according to guidelines like VDI/VDE 3518 [1214]. Corresponding trials will be conducted in the honey bee season 2019.

A theoretical consideration based on the balance equation of an ideal continuous batch reactor with constant emission source is applicable to estimate the temporal variation of the FA mass concentration in a hive during the FA application. However, the real air change is unknown and depends on various factors, like bee fanning, temperature inside the hive, and the gas thightness of the hive.

Our findings may serve as the technical basis for the development and further improvement of a more suitable detection method of FA in terms of monitoring the efficiency and effectiveness of the FA treatment against the bee-ectoparasite Varroa destructor. 


\section{References}

[1] P. Rosenkranz et al. "Biology and control of Varroa destructor", Journal of Invertebral Patholy 103 Suppl 1, S96-S119 (2010); doi: 10.1016/j.jip.2009.07.016

[2] S. Ramsey et al. "Varroa destructor feeds primarily on honey bee fat body tissue and not hemolymph", Proceedings of the National Academy of Sciences of the United States of America 116,5, 1792-1801 (2019); doi: 10.1073/pnas. 1818371116

[3] S. Bernardi, V.Ezio "Viral epidemiology of the adult Apis mellifera infested by the Varroa destructor mite." Heliyon 2,5 e00101 (2016); doi: 10.1016/j.heliyon.2016.e00101

[4] P. Neumann et al. „Varroa invasion and virus adaptation", Trends in Parasitology 28,9, 353354 (2012); doi: 10.1016/j.pt.2012.06.004

[5] P. Elzen et al. "Formic Acid Treatment for Control of Varroa destructor (Mesostigmata: Varroidae) and Safety to Apis mellifera (Hymenoptera: Apidae) Under Southern United States Conditions" Journal of economic entomology 97 , 1509-1512 (2004); doi: 10.1603/0022-049397.5.1509

[6] J. Amrine Jr., R. Noel "Formic acid fumigator for controlling varroa mites in honey bee hives", International Journal of Acarology 32,2, 115-124 (2006); doi: 10.1080/01647950608684452

[7] S. Bogdanov et al. "Determination of residues in honey after treatments with formic and oxalic acid under field conditions" Apidologie. 33, 399409 (2002); doi: 10.1051/apido:2002029.

[8] R. M. Underwood, R. W. Currie "The effects of temperature and dose of formic acid on treatment efficacy against Varroa destructor (Acari: Varroidae), a parasite of Apis mellifera (Hymenoptera: Apidae)." Experimental \& Applied Acarology 29,3, 303 (2003); doi: 10.1023/A:1025892906393

[9] S. Weiland, Nassenheider Evaporator Universal R - Long-Term Evaporator for Formic Acid, Operating Instructions, (2019-04-17), https://www.nassenheider.com/public/de/index. php?controller=attachment\&id_attachment=18.

[10] E. Müller-Erlwein, Chemical reaction engineering (in German), Volume 3, Springer Fachmedien, Wiesbaden (2015); doi: 10.1007/978-3-65809396-9.

[11] GESTIS Substance Database, Material Safety Data Sheet „Formic Acid”, (2019-04-24), http://gestis-

en.itrust.de/nxt/gateway.dll/gestis_en/011490.x $\mathrm{ml}$.

[12] VDI/VDE 3518-1:2011-05, Multigas sensors Terms, configuration, function and classification.

[13] VDI/VDE 3518-2:2014-12, Multigas sensors Function, classification and assessment.

[14] VDI/VDE 3518-3:2018-12, Multigas sensors Odour-related measurements with electronic noses and their testing. 